\title{
SISTEM PAKAR PENDIAGNOSA PENYAKIT BERBASIS MOBILE
}

\author{
Maimunah $^{1}$ \\ Gagas Pandu Wibowo ${ }^{2}$ \\ Dosen Jurusan Teknik Informatika STMIK Raharja ${ }^{1}$, Mahasiswa STMIK Raharja Jurusan Teknik \\ Informatika ${ }^{2}$ \\ Email:maimunah@raharja.info,gagas@raharja.info
}

Diterima: 4 Januari 2018/ Disetujui : 22 Januari 2018

\begin{abstract}
Some of the minor illnesses that often occur in the community are often ignored, if the disease is not treated immediately then the impact will be more severe and serious handling, therefore needed a system that can produce information about the possibility of disease in a person's body, so that can be handled more quickly to avoid dangerous diseases. In this study implemented the expert system to diagnose diseases based on mobile devices as the initial stage for first aid before consultation with the doctor. Therefore, it is necessary to design an expert system of mobile disease-based diagnostics, this system uses mobile technology for easy access and can be done anytime and anywhere, in addition to this system using a simple display that can facilitate the use. In this research, the researcher uses forward chaining method supported from data collection through observation and literature study. By simply selecting the age of the user and selecting the perceived symptoms, the user can immediately know the illness he or she is likely to suffer so that the handling of the disease can be done immediately.
\end{abstract}

Keywords : Expert System, Diagnosis Disease, Mobile

\begin{abstract}
ABSTRAK
Sebagian dari penyakit ringan yang sering terjadi pada masyarakat sering diabaikan, jika penyakit tersebut tidak segera ditangani maka dampaknya akan menjadi lebih parah dan serius penanganannya, oleh sebab itu diperlukan sebuah sistem yang dapat menghasilkan informasi mengenai kemungkinan penyakit pada tubuh seseorang, sehingga dapat ditangani lebih cepat untuk menghindari penyakit berbahaya. Dalam penelitian ini diimplementasikan sistem pakar untuk mendiagnosis penyakit berbasis mobile device sebagai tahap awal untuk pertolongan pertama sebelum konsultasi kepada dokter. Maka dari itu, perlu dirancang sebuah sistem pakar pendiagnosa penyakit berbasis mobile, sistem ini menggunakan teknologi mobile karena pengaksesan yang mudah dan dapat dilakukan kapanpun dan dimanapun, disamping itu sistem ini menggunakan tampilan yang sederhana sehingga dapat memudahkan dalam penggunaannya. Dalam penelitian ini peneliti menggunakan metode forward chaining yang didukung dari pengumpulan data melalui observasi dan studi pustaka. Dengan hanya memilih umur user dan memilih gejala-gejala yang dirasakan, user dapat segera mengetahui penyakit yang kemungkinan dideritanya sehingga penanganan penyakit dapat segera dilakukan.
\end{abstract}

Keywords : Sistem Pakar, Diagnosis Penyakit, Mobile

\section{PENDAHULUAN}

Kemajuan teknologi sekarang yang demikian pesatnya dapat menciptakan sebuah inovasi baru, salah satu teknologi yang sedang jadi perbincangan saat ini adalah teknologi berbasis mobile atau dikenal dengan sebutan mobile device. Teknologi ini berada di semua bidang, mulai dari berbisnis secara online hingga sarana pembelajaran online pun kerap di temukan. 
Sebagaimana diketahui bersama, bahwa semakin berkembangnya suatu peradaban maka rutinitas setiap manusia akan semakin bertambah sehingga diperlukan suatu sistem yang dapat memberikan kepraktisan bagi setiap orang, sehingga pengguna yang memerlukan suatu layanan sangat mudah dalam menggunakannya. Sistem dengan teknologi berbasis mobile dapat menciptakan solusi dari kendala yang ada karena menawarkan kepraktisan yang teramat sangat dapat memudahkanpenggunanya. Seluruh pelayanan yang ingin digunakan oleh user sudah ada dihadapan mereka.

Pada perkembangan teknologi sekarang ini bukan merupakan suatu halangan lagi apabila seorang pengguna ingin melakukan sesuatu hanya dengan sebuah handphone. Terlebih setiap produsen seluler pun sekarang bersaing untuk menyediakan fasilitas dan fitur terbaik hal itu tentu akan memudahkan setiap individu untuk terus dapat melakukan segala hal dengan perangkat mobile.

Salah satu pelayanan yang mungkin ditawarkan kepada masyarakat adalah pelayanan dibidang kesehatan berbasis mobile. Hal ini akan mempermudah masyarakat dalam melakukan konsultasi kesehatan, dan pastinya meringankan biaya yang seharusnya dikeluarkan dalam melakukan konsultasi kesehatan.

Pelayanan kesehatan ini akan mengadopsi cara kerja dari dokter dalam mendiagnosa penyakit dari seorang pasien dan akan sebisa mungkin memberikan penjelasan yang detil akan penyakit tersebut beserta resep obat yang akan dianjurkan kepada seorang pasien untuk mengobati penyakitnya. Sistem tersebut berusaha membandingkan gejala atau trauma yang dialami pasien dengan pusat data tentang penyakit serta gejalanya. Kemudian hasilnya akan diambil yang mempunyai tingkat kesesuaian yang paling tinggi. Setelah diketahui hasil penyakit seorang pasien, kemudian dapat diketahui juga formula yang sesuai untuk mengatasi penyakit pada pasien tersebut.

Namun tentunya peran kerja dari seorang dokter secara keseluruhan tidak akan digantikan oleh sistem ini. Sistem ini digunakan untuk gangguan kesehatan ringan,yang tidak memerlukan interaksi antara dokter dan pasiennya secara langsung.

\section{KAJIAN PUSTAKA}

Android merupakan sistem operasi bergerak (mobile operating system) yang mengadopsi sistem operasi linux, namun telah dimodifikasi.[1]

Forward chaining adalah salah satu metode dari sistem pakar yang mencari atau menelusuri solusi melalui masalah. Dengan kata lain metode ini melakukan pertimbangan dari fakta-fakta yang kemudian berujung pada sebuah kesimpulan yang berdasarkan pada fakta-fakta.[2]

Sistem Pakar secara umum, sistem pakar (Expert System) adalah sistem yang berusaha mengadopsi pengetahuan manusia ke komputer, agar komputer dapat menyelesaikan masalah seperti yang biasa dilakukan oleh para ahli [3]. Dengan sistem pakar ini, orang awam pun dapat menyelesaikan masalah yang cukup rumit yang sebenarnya hanya dapat diselesaikan dengan bantuan para ahli. Tujuan pengembangan sistem pakar sebenarnya tidak untuk menggantikan peran para pakar, namun untuk mengimplementasikan pengetahuan para pakar ke dalam bentuk perangkat lunak, sehingga dapat digunakan oleh banyak orang dan tanpa biaya yang besar. Untuk membangun sistem yang difungsikan untuk menirukan seorang pakar manusia harus bisa melakukan hal-hal yang dapat dikerjakan oleh para pakar. Untuk pembangun sistem yang seperti itu maka komponen-komponen dasar yang minimal harus dimiliki adalah sebagai berikut:

1. Antar muka (user interface).

2. Basis pengetahuan (knowledge base).

3. Mesin inferensi (Inference Engine).

Basis Pengetahuan (Knowledge Base) Basis pengetahuan berisi pengetahuan-pengetahuan dalam penyelesaian masalah, tentu saja didalam domain tertentu. Ada 2 bentuk pendekatan basis pengetahuan yang sangat umum digunakan, yaitu:

1. Penalaran berbasis aturan (Rule-Based Reasoning) Pada penalaran berbasis aturan, pengetahuan direpresentasikan dengan menggunakan aturan berbentuk: IF-THEN. Bentuk ini digunakan apabila 
kita memiliki sejumlah pengetahuan pakar pada suatu permasalahan tertentu, dan pakar dapat menyelesaikan masalah tersebut secara berurutan.

2. Penalaran berbasis kasus (Case-Based Reasoning) Pada penalaran berbasis kasus, basis pengetahuan akan berisi solusi-solusi yang telah dicapai sebelumnya, kemudian akan diturunkan suatu solusi untuk keadaan yang terjadi sekarang (fakta yang ada).

Mesin Inferensi (Inference Engine) Ada 2 cara yang dapat dikerjakan dalam melakukan inferensi, yaitu:

1. Forward Chaining (Pelacakan ke depan) Pencocokan fakta atau pernyataan dimulai dari bagian sebelah kiri (IF dulu).Dengan kata lain, penalaran dimulai dari fakta terlebih dahulu untuk menguji hipotesis.

2. Backward Chaining (Pelacakan ke belakang) Pencocokan fakta atau pernyataan dimulai dari bagian sebelah kanan (THEN dulu). Dengan kata lain, penalaran dimulai dari hipotesis terlebih dahulu, dan untuk menguji kebenaran hipotesis tersebut, harus dicari fakta-fakta yang ada dalam basis pengetahuan.

\section{Proses Diagnosis Penyakit}

Proses diagnosis merupakan perpaduan dari aktifitas intelektual dan manipulative. Diagnosis sendiri didefinisikan sebagai suatu proses penting pemberian nama dan pengklasifikasian penyakitpenyakit pasien, yang menunjukkan kemungkinan nasib pasien dan yang megarahkan pada pengobatan tertentu. Diagnosis banding, sebagaimana halnya dengan penelitian-penelitian ilmiah, didasarkan atas metode hipotesis. Dengan metode hipotesis ini menjadikan penyakit-penyakit begitu mudah dikenali hanya dengan suatu kesimpulan diagnosis.

Seorang dokter dalam mendiagnosa penyakit pasiennya dengan melalui tiga tahapan yang dilakukannya :

1. Wawancara

Pada periode ini seorang dokter bertanya mengenai gejala yang diderita pasien. Dimulai dari pertanyaan pertama tentang keluhan utama dari seorang pasien.Keluhan utama ini menceritakan mengenai gejala yang diderita oleh seorang pasien yang menyebabkan mengapa pasien mendatangi rumah sakit. Keluhan utama setiap pasien berbeda-beda walaupun penyakit yang diderita sama, tergantung dari tingkat ketahanan fisik seseorang terhadap suatu penyakit. Setelah diketahui keluhan utamanya maka selanjutnya dokter bertanya mengenai gejala-gejala yang ada pada pasien, setelah itu dilakukan perbandingan dengan kriteria suatu penyakit.

2. Pemeriksaan fisik

Tahapan ini merupakan tahapan dimana seorang dokter melihat kondisi fisik yang ada dari tubuh seorang pasien, mulai dari kepala hingga ujung kaki.Pengecekan ini dilakukan dikarenakan ada beberapa penyakit yang memiliki ciri-ciri yang dapat dikenali pada tanda-tanda fisik dari seorang pasien.

3. Pemeriksaan laboratorium

Pengecekan laboratorium merupakan tahapan dimana seorang dokter memerlukan bantuan dari laboratorium untuk memeriksa seorang pasien tentang suatu penyakit yang dideritanya, pengecekan ini akan menambah keakuratan seorang dokter dalam pendiagnosaannya. Pemeriksaan ini meliputi : pengambilan darah, tes urine, rontgen, dan lain-lain. Pemeriksaan laboratorium diperlukan untuk penyakit-penyakit tertentu yang sangat rumit dalam penentuan jenis penyakitnya.

\section{PERUMUSAN MASALAH}

Kesehatan dan penyakit adalah sesuatu yang saling berhubungan dan ada pada manusia. Faktanya banyak sekali penyakit yang pada akhirnya terlambat didiagnosa akan menjadi fatal, sedangkan dari beberapa penyakit sebelum mencapai tahap yang lebih kronis pada umumnya menunjukan gejala penyakit yang saat ini diderita oleh pasien tetapi masih dalam tahap yang ringan seperti sakit kepala, batuk, atau nyeri pada bagian tertentu. Ironisnya karena ketidakpahaman pada penyakit tersebut maka 
biasanya seorang penderita penyakit akan mengabaikan gejala-gejala ringan tersebut yang akan berpotensi fatal.

\section{KAJIAN LITERATUR}

1. Penelitian yang dibuat oleh Joshua Ricky Hartono, Gregorius Satia Budhi, dkk (2015) dari Universitas Kristen Petra dalam bentuk Jurnal ilmiah yang berjudul " Sistem Pakar Untuk Pertolongan Pertama Pada Penyakit Umum Menggunakan Metode Forward Chaining". Dalam pembuatan aplikasi ini, programmer melakukan konsultasi kepada pakar (dokter) untuk membuat knowledge based (basis pengetahuan), knowledge based system adalah sistem komputer yang mencoba untuk mereplikasi fungsi yang dilakukan oleh manusia, knowledge based system digunakan untuk menangkap, meneliti, dan mendistribusikan akses pengambilan keputusan. Berdasarkan hasil kuisioner didapat bahwa program aplikasi sistem pakar sebagai pertolongan pertama untuk penyakit umum ini dapat berjalan dengan baik dan mudah dalam penggunaannya [4].

2. Penelitian dengan "Sistem Pakar Pendiagnosa Penyakit Berbasis Web". Penelitian ini dibuat oleh Dedy Kurniawan (2013). Penelitian ini membahas tentang informasi penyakit yang dibuat dalam sistem web. Sistem ini digunakan untuk mempermudah pasien yang ingin mengetahui penyakit awal yang dideritanya supaya pasien ini tidak perlu pergi dahulu ke dokter untuk berkonsultasi penyakitnya. Sistem pakar pendiagnosa penyakit ini dapat diakses darimana pun sehingga sangat memudahkan seseorang dalam mendiagnosa penyakitnya. Sistem pakar ini dibuat menggunakan PHP dan berjalan di server APACHE dengan basis data MySQL[5].

3. Penelitian dengan judul " Perancangan Sistem Pakar Untuk Diagnosa Penyakit Anak ", Penelitian ini dibuat oleh Shafa Dhany tahun 2008. Sistem pakar ini dibuat untuk mengetahui penyakit yang terjadi pada anak sebagai media untuk mendiagnosa penyakit pada iklim tropis terutama untuk balita, dengan berbasis pengetahuan yang dinamis. Pengetahuan ini diperoleh berdasarkan sumber-sumber penelitian dan seminar yang telah dilakukan oleh seorang pakar/ahli dalam bidangnya, dan juga dari buku-buku yang berkaitan dengan penyakit anak. Basis pengetahuan dalam sistem ini disusun dengan sedemikian rupa dan disimpan kedalam sebuah database dengan beberapa tabel yaitu tabel penyakit, tabel aturan, dan tabel gejala agar lebih memudahkan kinerja dari sebuah sistem dalam pengambilan kesimpulan. Penarikan hasil kesimpulan dalam sistem ini memakai metode infrensi forward chaning. Sistem ini menunjukkan gejala yang akan dipilih oleh user, dan dari gejala yang ditunjuk oleh user akan membawa user pada pilihan gejala berikutnya kemudian pada tahap akhir akan didapatkan hasilnya. Pada tahap akhir penyakit, gejala yang diderita oleh user serta penyebab dan cara penanggulangannya akan ditunjukkan oleh sistem. Selain itu, sistem ini dapat pula menampilkan informasi anak seperti gizi anak dan keamanan [6].

4. Penelitian dengan judul " Hubungan Faktor Resiko Umur, Jenis Kelamin Dan Kepadatan Hunian Dengan kejadian Penyakit TB Paru Di Desa Wori Kecamatan Wori ", Penelitian ini dibuat oleh Jendra F.J Dotulong, Margareth R. Sapulete DKK pada tahun 2015. Penelitian ini membahas tentang penyakit Tuberkolosis (TB), Tuberkolosis adalah suatu penyakit infeksi yang disebabkan oleh bakteri Mycrobacterium tuberculosis sebagian besar kuman TB menyerang paru-paru, tetapi dapat juga mengenai organ tubuh lainnya. Dalam penelitian ini peneliti menggunakan studi deskriptif analitik dengan metode cross sectional. Sampel penelitian sebanyak 97 responden. Analisis data dilakukan dengan uji chi square untuk mengetahui deskripsi dan hubungan faktor resiko dengan kejadian tuberculosis paru. Hasil analisis bivariat yang terbukti berhubungan dengan kejadian tuberculosis paru adalah; umur $(\mathrm{p}=0,012)$ dan jenis kelamin $(\mathrm{p}=0,012)$ dan jenis kelamin $(\mathrm{p}=0,000)$. Dari keseluruhan hasil penelitian bahwa factor resiko yang di teliti yang berhubungan dengan kejadian tuberculosis paru adalah umur dan jenis kelamin [7]. 


\section{PEMBAHASAN}

Untuk menyelesaikan masalah yang ada pada masalah diatas, maka diperlukan beberapa alternatif pemecahan dari permasalahan yang dihadapi, antara lain :

1. Dapat dibuatkan sebuah sistem agar bisa mempermudah pasien dalam mengetahui penyakit awal yang dideritanya, agar pasien tersebut tidak perlu pergi berkonsultasi kepada dokter untuk wawancara, pengecekan fisik, atau pengecekan lab sehingga penyakit yang diderita pasien dapat diketahui.

2. Dapat memberikan hasil kesimpulan penyakit yang diderita oleh user dan informasi tentang resep obat yang harus dikonsumsi oleh user dengan dosis minimum agar tidak menimbulkan efek yang berlebih pada obatnya.

3. Dapat memberikan kiat-kiat dalam menjaga kesehatan agar tidak mudah terjangkit penyakit.

\section{Tabel Basis Pengetahuan Penyakit}

Untuk mengetahui Penyakit yang diderita oleh pasien pada sistem berbasis mobile ini maka dibuatlah sebuah tabel basis pengetahuan yang berisikan gejala, umur dan penyakit serta solusinya :

\begin{tabular}{|c|c|c|c|c|c|}
\hline NO. & $\begin{array}{l}\text { GEJALA } \\
\text { UTAMA }\end{array}$ & GEJALA & UMUR & PENYAKIT & SOLUSI \\
\hline 1. & Bersin-bersin & $\begin{array}{l}\text { Sakit kepala dan } \\
\text { Demam }\end{array}$ & Segala usia & Flu & $\begin{array}{l}\text { Istirahat yang } \\
\text { cukup serta } \\
\text { mengkonsumsi } \\
\text { Paracetamol / Ibu } \\
\text { Profen. }\end{array}$ \\
\hline 2. & $\begin{array}{l}\text { Sakit kepala } \\
\text { Sebelah }\end{array}$ & $\begin{array}{l}\text { Mual, Hidung } \\
\text { tersumbat, } \\
\text { penglihatan } \\
\text { melihat kilatan } \\
\text { cahaya }\end{array}$ & $20>$ & Migrain & $\begin{array}{l}\text { Mengkonsumsi } \\
\text { obat yang } \\
\text { mengandung } \\
\text { Asteaminofen dan } \\
\text { Paracetamol. }\end{array}$ \\
\hline 3. & $\begin{array}{l}\text { Sakit } \\
\text { Tenggorokan }\end{array}$ & $\begin{array}{l}\text { Demam tinggi, } \\
\text { Pembengkakan } \\
\text { Amandel, dan } \\
\text { Batuk, Hidung } \\
\text { berlendir }\end{array}$ & Segala usia & Faringitis & $\begin{array}{l}\text { Hindari polusi, } \\
\text { debu, serta asap dan } \\
\text { banyak minum air } \\
\text { putih. }\end{array}$ \\
\hline 4. & $\begin{array}{l}\text { Batuk lendir } \\
\text { kental }\end{array}$ & $\begin{array}{l}\text { Sesak napas, } \\
\text { Sakit } \\
\text { tenggorokan, } \\
\text { Hidung } \\
\text { tersumbat. }\end{array}$ & 17> & Bronkitis & $\begin{array}{l}\text { Mengkonsumsi } \\
\text { bahan alami seperti } \\
\text { tanaman Ciplukan, } \\
\text { bunga sepatu dan } \\
\text { jahe. }\end{array}$ \\
\hline 5 . & $\begin{array}{l}\text { Bercak kulit } \\
\text { yang lebih } \\
\text { terang }\end{array}$ & $\begin{array}{l}\text { Kulit menjadi } \\
\text { putih bulat kecil, } \\
\text { gatal-gatal akibat } \\
\text { cuaca panas. }\end{array}$ & Segala usia & Panu & $\begin{array}{l}\text { Obati dengan } \\
\text { memakai } \\
\text { salep/krim kulit yg } \\
\text { mengandung bahan } \\
\text { seperti klotrimazol, } \\
\text { belerang dan }\end{array}$ \\
\hline
\end{tabular}




\begin{tabular}{|c|c|c|c|c|c|}
\hline & & & & & selenium sulfide. \\
\hline 6. & $\begin{array}{l}\text { Luka dan } \\
\text { Lepuh pada } \\
\text { bagian kulit } \\
\text { tertentu }\end{array}$ & $\begin{array}{l}\text { Muncul Ruam } \\
\text { bintik kecil, Sakit } \\
\text { kepala, Demam } \\
\text { dan tubuh lemah. }\end{array}$ & Segala usia & Herpes & $\begin{array}{l}\text { Olesi dengan krim } \\
\text { kulit yg } \\
\text { mengandung } \\
\text { Antibiotik, } \\
\text { Melakukan } \\
\text { Vaksinasi. }\end{array}$ \\
\hline 7. & Nyeri perut & $\begin{array}{l}\text { Nyeri pada } \\
\text { uluhati, Mual, } \\
\text { Perut kembung, } \\
\text { cepat } \\
\text { Kenyang,dan } \\
\text { Bersendawa. }\end{array}$ & Segala usia & Maag & $\begin{array}{l}\text { Mengkonsumsi } \\
\text { obat yg } \\
\text { mengandung } \\
\text { Antasida, jgn } \\
\text { memakan makanan } \\
\text { pedas. }\end{array}$ \\
\hline 8. & $\begin{array}{l}\text { Nyeri pada } \\
\text { bagian bawah } \\
\text { kanan Perut }\end{array}$ & $\begin{array}{l}\text { Mual, Muntah- } \\
\text { muntah, Meriang, } \\
\text { Sakit seluruh } \\
\text { badan. }\end{array}$ & Segala usia & Usus Buntu & Pergi ke Dokter \\
\hline 9. & $\begin{array}{l}\text { Demam } \\
\text { melebihi } 7 \\
\text { hari }\end{array}$ & $\begin{array}{l}\text { Bintik-bintik } \\
\text { merah pada Kulit, } \\
\text { Demam parah. }\end{array}$ & Segala usia & $\begin{array}{l}\text { Demam } \\
\text { berdarah }\end{array}$ & Pergi ke Dokter \\
\hline 10. & $\begin{array}{l}\text { Batuk dan } \\
\text { disertai } \\
\text { bercak darah }\end{array}$ & $\begin{array}{l}\text { Batuk berdahak } \\
>3 \text { minggu, } \\
\text { demam, tidak } \\
\text { napsu makan }\end{array}$ & 15> & TBC & Pergi ke Dokter \\
\hline 11. & $\begin{array}{l}\text { Sakit } \\
\text { Tenggorokan }\end{array}$ & $\begin{array}{l}\text { Demam, Panas } \\
\text { dingin, Batuk }\end{array}$ & $21<$ & Difteri & Pergi ke dokter \\
\hline
\end{tabular}

\section{Analisis Prosedur}

Prosedur adalah susunan kegiatan yang sesuai dari berbagai macam tahapan-tahapan yang berupa instruksi yang harus dilakukan oleh seseorang. 
Prosedur mendiagnosa penyakit :

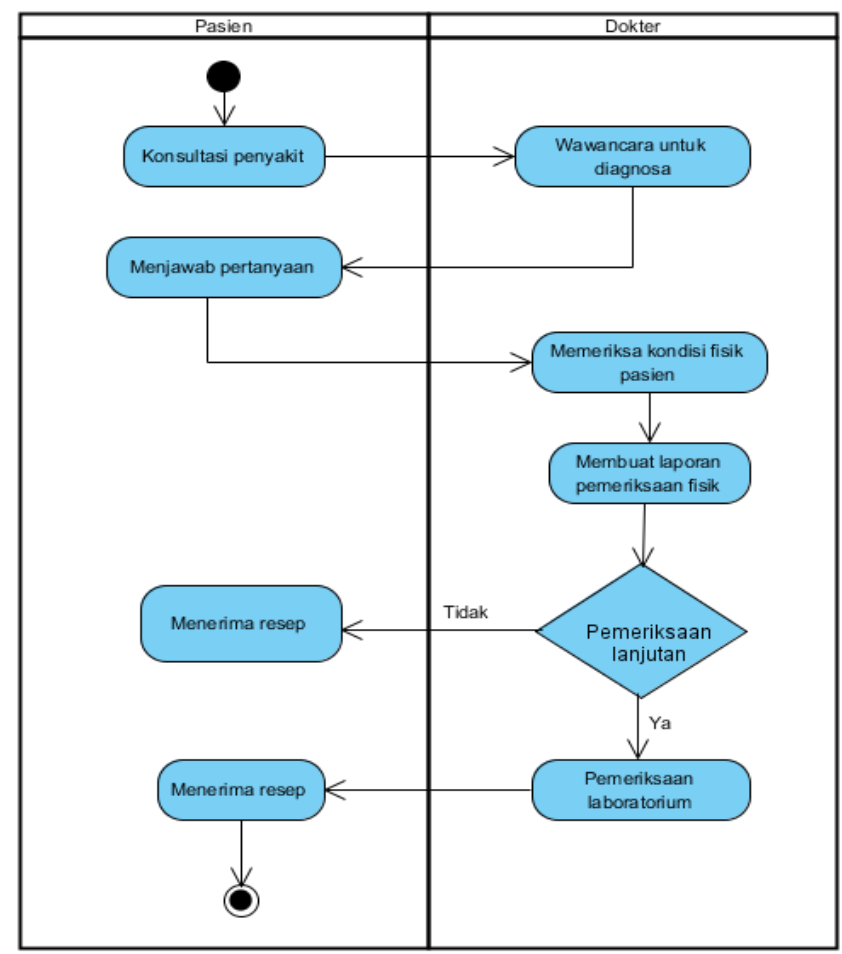

Gambar 1. Diagram Prosedur Konsultasi Penyakit

1. Pasien mempunyai penyakit lalu konsultasi kepada dokter.

2. Dokter mewawancarai pasien dengan memberikan beberapa pertanyaan.

3. Pasien menjawab pertanyaan yang ditanyakan oleh dokter.

4. Dokter memeriksa kondisi pasien agar menambah tingkat keyakinan dari hasil diagnosa.

5. Proses pemeriksaan dilanjutkan kepemeriksaan laboratorium apabila data diperoleh dari pemeriksaan sebelumnya kurang apabila tidak, pasien langsung diberikan resep obat.

\section{Perancangan Sistem}

Sistem yang dibuat dalam penelitian ini adalah diagnosis penyakit.dengan menyimpan beberapa pengetahuan yang telah disimpan pada field database sebagai basis pengetahuan, sistem ini menggunakan metode forward chaining dengan bahasa pemrograman Java Android dan database mysql.

Sistem ini dibangun dengan struktur modul-modul sebagai berikut :

1. Menu utama.

2. Menu konsultasi.

3. Menu tentang aplikasi.

4. Menu tips menjaga kesehatan.

Perancangan sistem ini menjelaskan kepada user, tentang diagnosa penyakit agar user lebih mudah mengetahui penyakit dari gejala yang timbul tanpa perlu pergi ke dokter. 


\section{Use Case Diagram}

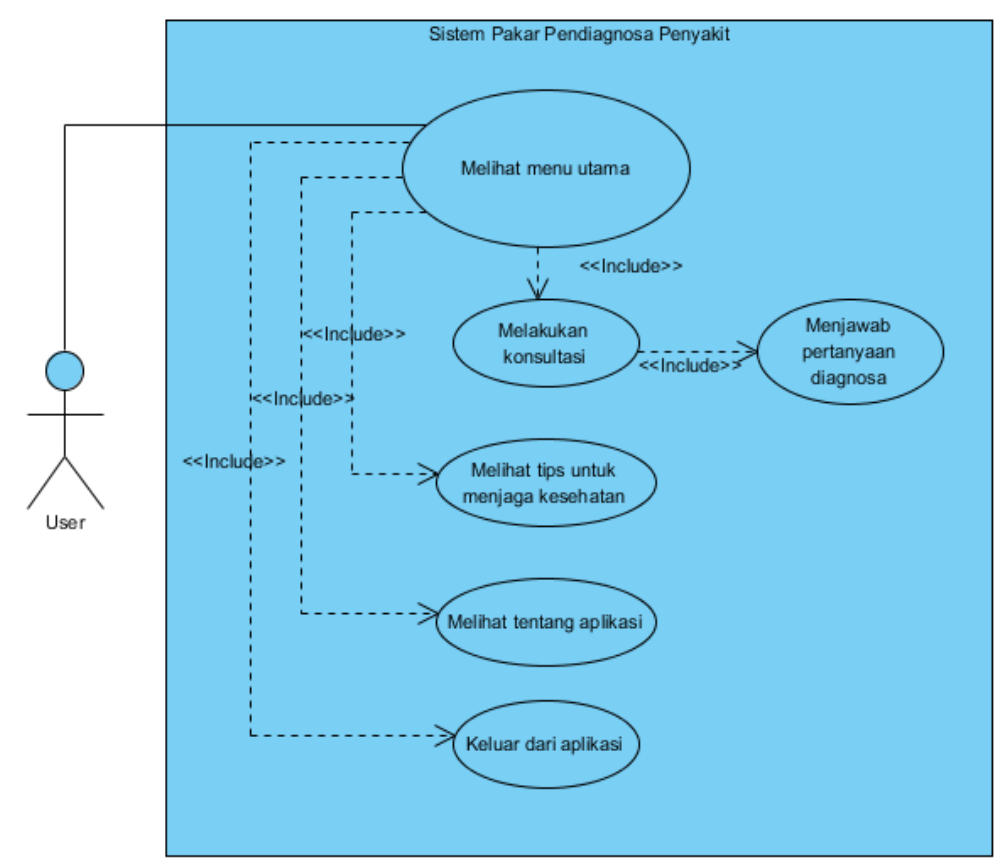

Gambar 2. Use Case Diagram Sistem Pakar Pendiagnosa Penyakit

Pada use case diatas, maka dapat mendeskirpsikan hal-hal sebagai berikut :

1. User merupakan aktor

2. User membuka aplikasi dan melihat menu utama

3. User berkonsultasi untuk mengetahui penyakitnya

4. User menjawab pertanyaan diagnosa

5. User melihat tips menjaga kesehatan

6. User melihat tentang aplikasi

7. User meninggalkan aplikasi

\section{Activity Diagram}

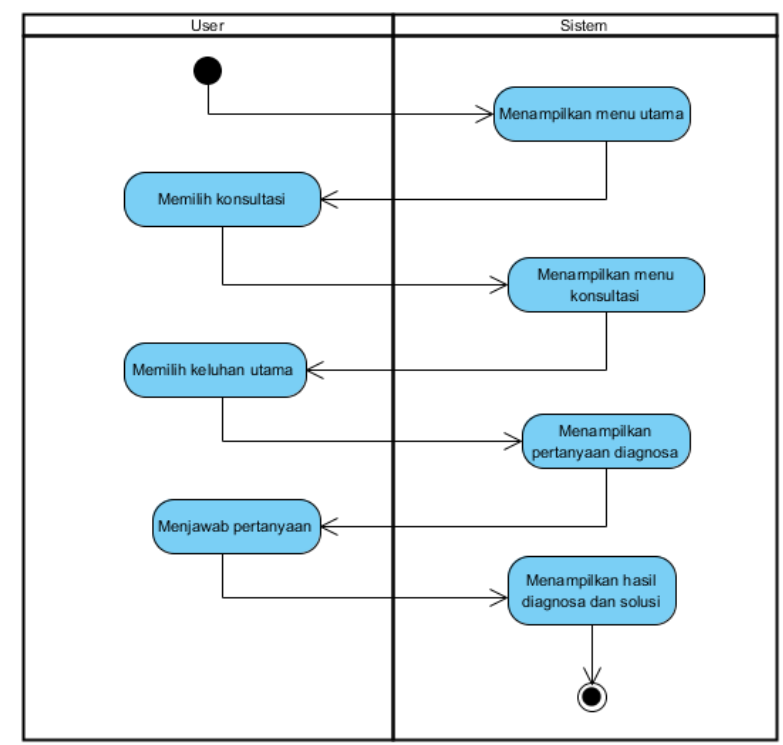


Gambar 3. Diagram Activity Sistem Pakar Pendiagnosa Penyakit

Pada activity diagram diatas, maka dapat mendeskirpsikan hal-hal sebagai berikut :

1. Sistem menampilkan menu home/utama

2. User memilih menu konsultasi

3. Sistem menampilkan menu konsultasi

4. User memilih keluhan utama

5. Sistem menampilkan pertanyaan untuk diagnosa penyakit

6. User menjawab pertanyaan diagnosa

7. Sistem menyimpulkan untuk menampilkan hasil diagnose

\section{Class Diagram}

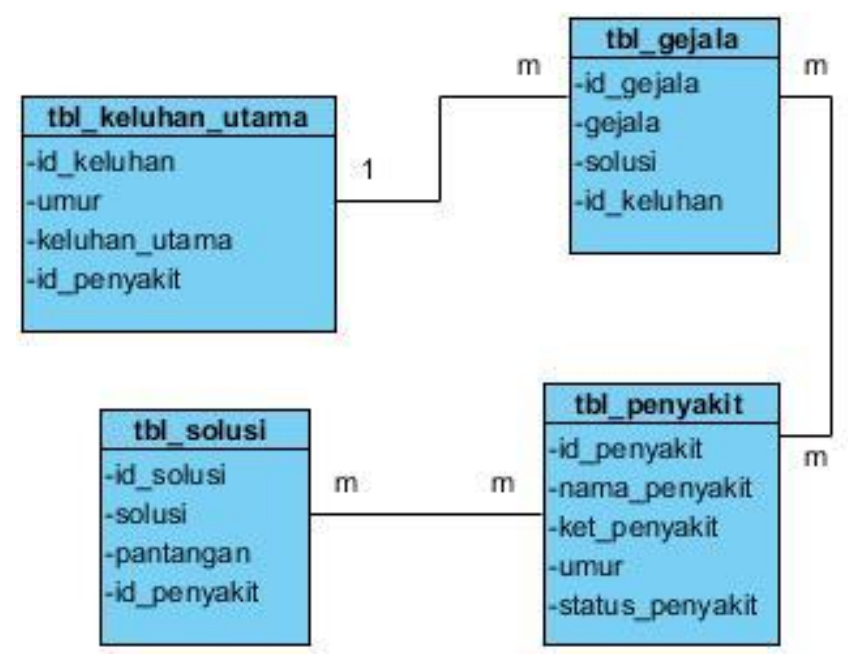

Gambar 4. Class Diagram Sistem Pakar Pendiagnosa Penyakit

Pada class diagram diatas, maka dapat mendeskirpsikan hal-hal sebagai berikut :

1. Class / table penyakit memiliki relasi dengan keluhan utama karena untuk mengetahui penyakit user perlu memasukkan keluhan

2. Class/table gejala memiliki relasi dengan solusi dan keluhan utama karena setelah user memilih keluhan utama lalu akan muncul pertanyaan gejala apa yang dirasakan untuk menyimpulkan solusinya

3. Class table solusi memiliki relasi dengan penyakit karena solusi dari sebuah penyakit akan diketahui bila mengetahui penyakitnya

\section{PROTOTYPE TAMPILAN}

Dari hasil gambaran diagram yang ada dapat dibuatkan kedalam sebuah prototype tampilan sistem pakar untuk memberikan penjelasan terhadap sistem pakar yang berbasis mobile ini : 


\section{Prototype Tampilan Menu Utama}

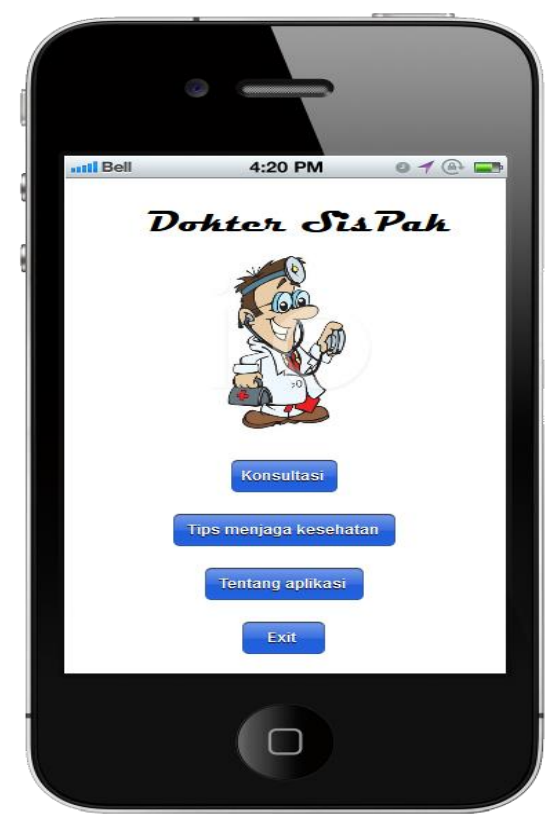

Gambar 5.Prototype Menu Utama

Gambar 5. Merupakan prototype tampilan menu utama sistem pakar pendiagnosa penyakit.User dapat melakukan konsultasi dengan memilih menu konsultasi.

Menu Konsultasi : User dapat melakukan konsultasi penyakit yang diderita olehnya.

Menu Tips kesehatan : Menu ini berisi berbagai macam cara untuk menjaga kesehatan.

Menu Tentang Aplikasi : Menu ini berisikan versi aplikasi dan nama dari pembuat aplikasi.

Menu Exit : Menu ini user digunakan untuk keluar dari aplikasi.

\section{Prototype Tampilan Menu Konsultasi}

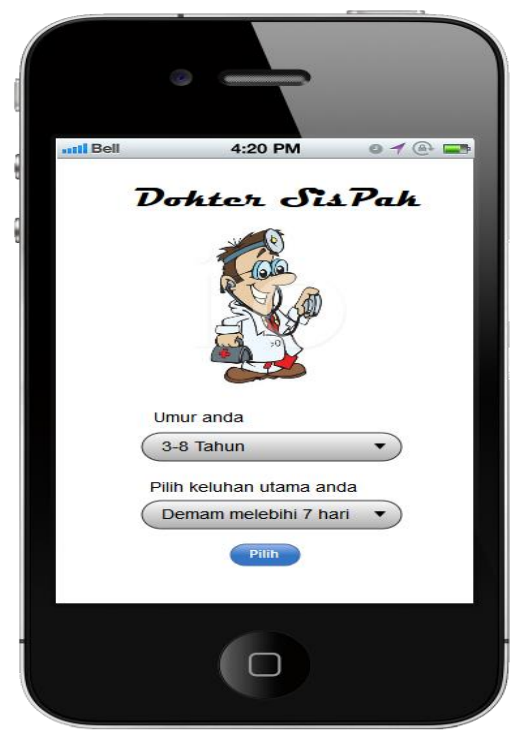

Gambar 6.Prototype Menu Konsultasi 
Gambar 6. Merupakan prototypetampilan menu konsultasi pada sistem pakar ini.Setelah user memilih menu konsultasi, maka user dapat memilih umur dan memilih gejala utama yang dialami pada user.

Menu Umur : User dapat memilih umur pasien pada menu ini.

Menu Keluhan : Menu ini digunakan untuk memilih penyakit yang diderita oleh pasien

\section{Prototype Tampilan Pertanyaan Diagnosa}

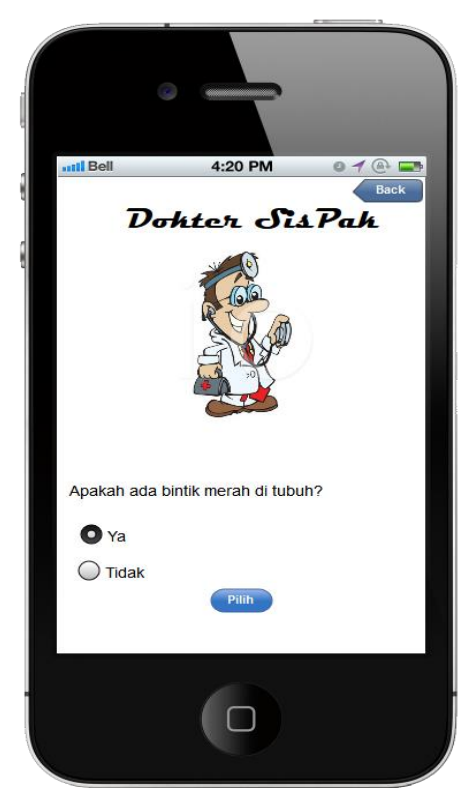

Gambar 7.Prototype Tampilan Pertanyaan Diagnosa

Gambar 7. Merupakan prototypetampilan pertanyaan diagnosa. Setelah user memilih umur dan gejala utama, lalu muncul pertanyaan diagnosa yang akan dijawab oleh user untuk mendapatkan hasil penyakit yang diderita.

Radio button Ya $\quad$ : Pilihan ini digunakan jika pasien mengalami gejala sesuai dengan pertanyaan

Radio button Tidak : Pilihan ini digunakan jika pasien tidak mengalami gejala sesuai dengan pertanyaan

\section{Prototype Tampilan Hasil Diagnosa}




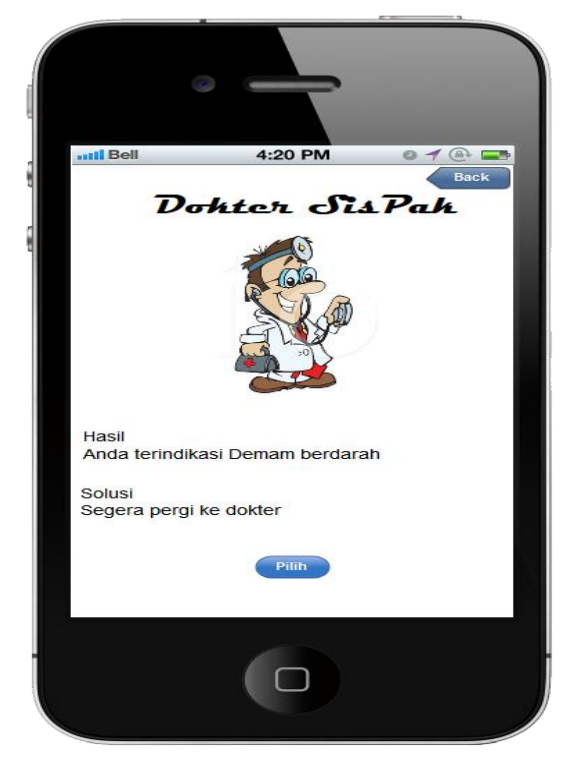

Gambar 8.PrototypeTampilan Hasil Diagnosa

Gambar 8. Merupakan prototype tampilan hasil diagnosa. Setelah user menjawab seluruh pertanyaan diagnosa, maka sistem menunjukkan hasil dari penyakit yang dialami oleh user dan solusi untuk menanganinya.

Hasil diagnosa : Tampilan ini berisikan hasil dari semua proses yang dilakukan user, serta terdapat penangan yang perlju dilakukan terhadap pasien.

\section{KESIMPULAN}

Dari hasil pembahasan penelitian mengenai sistem pakar pendiagnosa penyakit diatas dapat diambil beberapa kesimpulan, diantaranya :

1. Sistem pakar diagnosa penyakit berbasis mobile ini dibuat dengan metode forward chaining dengan menggunakan bahasa pemrograman java android dan database mysql.

2. Sistem pakar ini dibuat berbasis mobile agar user dapat lebih mudah mengakses sistem ini setiap saat.

3. Dengan dibuatnya sistem pakar ini proses diagnosa akan lebih cepat dibandingkan dengan diagnosa penyakit yang sebelumnya harus melaui beberapa tahap, karena sistem ini menyimpulkan hasil penyakit awal berdasarkan input gejala yang telah diberikan user.

4. Hasil penyakit merupakan representasi dari macam-macam penyakit berdasarkan gejala yang dirasakan yang telah diinput oleh user.

5. Dengan dibuatnya sistem pakar pendiagnosa penyakit ini diharapkan semua kalangan dapat menggunakan diberbagai macam jenis smartphone.

\section{DAFTAR PUSTAKA}

[1] Safaat, Nazzarudin. 2011. Pemrograman Aplikasi Mobile Smartphone dan Tablet PC Berbasis Android. Informatika. Bandung.

[2] Giarratano, J.C dan Riley, GD 2005. Expert Systems Principle and Programming Fourth Edition. New York: Course Technology.

[3] Andi, Penerbit, Tim. 2003. Pengembangan Sistem Pakar Menggunakan Visual Basic. Penerbit Andi, Yogyakarta.

[4] Hartono J.R, Budhi G.S, dan Dewi L.P . 2015. "Sistem Pakar Untuk Pertolongan Pertama Pada Penyakit Umum Menggunakan Metode Forward chaining” . Jurnal Ilmiah .Universitas Kristen Petra:

Surabaya. 
[5] Kurniawan Dedy. 2013. "Sistem Pakar Pendiagnosa Penyakit Berbasis Web”. Skripsi. Universitas Indonesia: Depok.

[6] Dhany Safia. 2008. "Perancangan Sistem Pakar Untuk Diagnosa Penyakit Anak". Skripsi. Universitas Sumatera Utara: Medan.

[7] Dotulong Jendra F.J, Sapulete Margareth R., dan Kandou Grace D. 2015. "Hubungan Faktor Risiko Umur, Jenis Kelamin Dan Kepadatan Hunian Dengan Kejadian Penyakit TB Paru Di Desa Wori Kecamatan Wori”. Jurnal Kedokteran Komunitas dan Tropik. Fakultas Kedokteran Universitas Sam Ratulangi Manado. 